\title{
El tercer gobierno peronista. Primeras explicaciones sobre su fracaso ${ }^{1}$
}

\author{
The third Peronist government. \\ First explanations about his failure
}

María Estela Spinelli ${ }^{2}$

\section{Resumen:}

Los años del tercer gobierno peronista (1973-1976), con las presidencias de Héctor J. Cámpora, Raúl Lastiri, Juan Domingo Perón y María Estela Martínez de Perón, venían a concretar la larga espera de sus antiguos partidarios desde la caída en el ‘ 55 y las expectativas de vastos sectores de las clases medias que a derecha e izquierda se fueron radicalizando, y en buena medida «peronizando» en esos años. Sin embargo, poco o nada resultó como se había esperado... Los primeros estudios históricos sobre los clivajes de la política en esta experiencia, pusieron distintos énfasis en la explicación de su fracaso.

Palabras clave: historiografía; posperonismo; explicaciones

\begin{abstract}
:
The third peronist government, between 1973-1976, comprising the presidencies of Héctor J. Cámpora, Raúl Lastiri Juan Domingo Perón and María Estela Martínez de Perón, was presumed to fulfil to the long postponed anticipations of its followers since the downfall of 1955, and the expectations of the middle classes, that either to the wright or the left of the political spectrum, became radicalized and in a considerable degree «peronized» in those years. However, it was very far away from their hopes. Historical studies on the political cleavages in this experience have placed emphasis in different factors to explain its failure.
\end{abstract}

Keywords: historiography; post-Peronism; explanations

\section{Introducción}

Revisar la producción académica de los tempranos '80 sobre este traumático proceso, ha sido nuestro principal interés. Esta nos pone en contacto con distintos acercamientos elaborados durante estos años, desde

\footnotetext{
${ }^{1}$ Trabajo recibido el 28/08/2020. Aceptado el 20/10/2020.

${ }^{2}$ Universidad Nacional del Centro. Contacto: mariaestelaspinelli@gmail.com
} 
campos disciplinares e interpretativos diversos que revelan el diálogo y la modernización de las ciencias sociales en nuestro medio académico. Los temas y problemas que concitaron mayor atención fueron, además de Perón y de los líderes del peronismo, especialmente Isabel Perón, los gobiernos peronistas que se sucedieron entre 1973 y 1976, los sindicatos, la violencia, la represión, las organizaciones armadas -fundamentalmente Montoneros- las movilizaciones y conflictos, los militares, la juventud. Un cuadro, en fin, con distintos espacios iluminados sobre las expectativas, las acciones y las tragedias ocurridas.

La idea del presente artículo ha sido centrarnos, especialmente, en los primeros estudios que intentaron elaborar explicaciones sobre la naturaleza de los conflictos y los instrumentos utilizados, en cada caso, por los cuatro gobiernos peronistas que se sucedieron en tan breve período, incluyendo los referidos a los actores de mayor gravitación en el último fracaso democrático de la Argentina del siglo XX.

En el campo de la problemática política argentina, un primer conjunto de trabajos estudió la relación entre civiles y militares, editados en nuestro país en los inicios de la década de 1980, a los que siguieron contribuciones y debates que analizaron las alternativas de este proceso, en el contexto de la transición democrática. ${ }^{3}$ Los ejes fueron la recurrencia en el autoritarismo y la debilidad de la tradición democrática en América Latina, en general y de la Argentina en particular. ${ }^{4}$ Desde ese presente analizan este pasado conflictivo y desde el campo disciplinar nos ponen en contacto con la renovación de los estudios históricos en el campo de la política del tiempo cercano -que entre nosotros tenían antecedentes en los trabajos de Gino Germani, José Luis Romero y Tulio Halperín Donghi, en los tempranos sesentas- y formulan nuevas preguntas que revalorizan las formas y los valores democráticos, desde el campo de las ideas, el discurso, la cultura y las prácticas políticas.

\footnotetext{
${ }^{3}$ Este ciclo de producción historiográfica en nuestro país se inicia a partir de los trabajos de Potash (1981); Rouquié (1981 y 1982); O’Donell (1982), Cavarozzi (1983). Posteriormente, entre otros pueden citarse Rouquié y Schvarzer (1985), Calvert (1989), Waldman y Garzón Valdéz (1983), Pinto (1988). Dentro de la temática, orientado a la divulgación, Luna (1983).

${ }^{4} \mathrm{Al}$ respecto, ver Lesgart (2002) y Spinelli (2008).
} 


\section{El contexto histórico}

El deshielo político del «Proceso de Reorganización Nacional» iniciado en marzo de 1976, comenzó a producirse gradualmente desde el ascenso del general Roberto Eduardo Viola a la presidencia del gobierno de facto, a comienzos de 1981 (Tcach, 1996). Este realizó una apertura hacia el centro-derecha del espectro político, con la presencia de algunos de sus dirigentes en el gabinete, mientras buscó congraciarse con radicales y peronistas. Hacia mediados de año se conformó la Multipartidaria, organismo auto convocado, que reunió a los principales partidos políticos. A todo esto ya era visible una creciente liberalidad de la prensa que adquirió nueva dinámica, mientras en el campo cultural comenzó a hacerse evidente la creciente ruptura entre la sociedad y el régimen, a lo que se sumaron, avanzado el año, peculiares manifestaciones populares de resistencia, procesiones a San Cayetano y a la basílica de Luján (Novaro y Palermo, 2003). ${ }^{5}$

El breve gobierno del general Viola tuvo marcadas resistencias entre los altos mandos de las Fuerzas Armadas, provenientes de los sectores que ambicionaban proyectar en el tiempo el Proceso de Reorganización Nacional. Este fue interrumpido cuando la Junta Militar lo destituyó, designando en su lugar al general Leopoldo Fortunato Galtieri, hacia fines de diciembre del ' 81 .

El proyecto del nuevo presidente de facto era dar nuevo impulso al régimen militar, con un golpe de timón que permitiera un reposicionamiento internacional. En esos momentos las resistencias sociales eran cada vez más explícitas, incluyeron manifestaciones callejeras y huelgas, como la convocada por la CGT el 30 de marzo de 1982. El plan, consensuado con la Armada consistió en la recuperación de las islas Malvinas a través de la ocupación de las mismas, que tuvo una inmediata y efímera adhesión popular, pero resultó en un estrepitoso fracaso militar y político, lo cual profundizó el descrédito y marcó el fin de la última dictadura militar en la Argentina del siglo XX.

El tiempo de la transición resultó complicado. La última Junta Militar designada luego de la renuncia de Galtieri, presidida por el gene-

\footnotetext{
${ }^{5}$ Un reflejo de la apertura del debate político y del espacio del liberalismo en él, entre otros, en Floria (1981) del que participaron: Roberto Cortés Conde, Ezequiel Gallo, Manuel Mora y Araujo, Carlos Floria, Natalio Botana, Enrique Zuleta Puceiro, Jorge Enrique Cermesoni, Félix Peña, Carlos Pérez Llana.
} 
ral Reinaldo Bignone, anunció la salida electoral, no sin antes buscar pactar una retirada lo menos costosa posible, pero las condiciones no estaban dadas. La cuestión de los desaparecidos, ${ }^{6}$ que sistemáticamente quisieron dar por cerrada los militares, instaló una dimensión ética imposible de soslayar para un sector creciente de la sociedad que se expresó públicamente, a lo que se sumaron los reclamos y movilizaciones generados por la crisis económica y una necesidad de participación política que se transparentó en afiliaciones masivas a los partidos políticos, entre los que sobresalieron el Peronismo y el Radicalismo. Este último hizo de la Democracia su bandera y ganó la elección de 1983, con el liderazgo de Raúl Alfonsín, ${ }^{7}$ que asumió el 10 de diciembre.

El proceso de normalización institucional, y el debate político a raíz de la sorpresa que había significado la primera derrota del peronismo en una elección limpia, motivó reflexiones y explicaciones encontradas, e hizo cada vez más visibles las transformaciones en la cultura política, que en una sociedad donde los sentimientos políticos nacionales y populares estaban muy arraigados, comenzaba a operar una nueva valoración de la libertad, del estado de derecho y de la democracia.

\section{El medio académico}

Al comenzar la década del '80 la producción académica presentaba grados de desarrollo diversos en Ciencias Sociales y Humanidades, con un significativo avance en Historia Económica, Social y la Sociología política, iniciados en la década del sesenta (Sigal, 1991). Entre los profesionales innovadores, vinculados al ámbito académico internacional, algunos realizaron estadías de investigación y de trabajo en universidades europeas y norteamericanas, mientras otros realizaron estudios de postgrado. Se dio nuevo impulso a la investigación de los estudios históricos ${ }^{8}$ y se fundaron nuevos centros de investigación privados.

Desde el punto de vista institucional, en la esfera estatal la situación fue mayormente distinta. Las Universidades Nacionales, tanto las

\footnotetext{
${ }^{6}$ Interna e internacionalmente conocida y denunciada, había dado lugar, entre otras, a la misión de la Comisión Interamericana de Derechos Humanos de la OEA, cuyo informe se hizo público en abril de 1980.

${ }^{7} \mathrm{Al}$ respecto, ver: Romero (1994) y Novaro (2006).

${ }^{8} \mathrm{Al}$ respecto puede verse, entre otros: Hora y Trímboli (1994), texto que contiene catorce entrevistas a destacados intelectuales dedicados a la historia argentina.
} 
de mayor prestigio y trayectoria -Buenos Aires, Córdoba, La Plata y otras- como las de creación más reciente, estuvieron intervenidas por los gobiernos militares y sometidas a un estricto control ideológico y político, con parte de sus docentes, estudiantes e investigadores emigrados o cesanteados, ${ }^{9}$ siendo sus desarrollos en investigación histórica, social y política en los años del Proceso escasos y en buena medida atados a un paradigma anterior.

Luego de la restauración democrática, hacia fines de 1983 y comienzos de 1984, las universidades fueron gradualmente normalizadas, parte de los docentes separados durante el Proceso fueron reincorporados, se restableció la vigencia de la Reforma Universitaria de 1918 suspendida desde 1966- y en algunas de ellas se abrió un proceso de modernización académica que en algunos años dinamizó, con distintos ritmos, la investigación y el intercambio académico (Halperín Donghi, 1986; Romero, 1996). Se abrieron debates sobre el pasado político y sus actores, que ya estaban en el debate público y sobre las perspectivas de renovación académica que abría la naciente democratización.

\section{Los primeros estudios sobre el tercer gobierno peronista}

En ese particular momento intelectual y político que la democracia inauguró fueron editadas, entre otras, las primeras investigaciones sobre el tercer gobierno peronista, la mayor parte de las cuales fueron realizadas desde el exterior por investigadores argentinos, hacia fines de los años setenta. Dicho gobierno había estado precedido por el intenso fenómeno de politización y peronización de los sectores medios iniciado en los sesentas, por grandes movilizaciones, debates ideológicos, enfrentamientos armados y el para vastos sectores sociales anhelado retorno del general Perón al país y al poder. ${ }^{10}$

Los primeros estudios provenientes de la investigación académica, editados en la década de $1980,{ }^{11}$ elaboraron desde distintas perspectivas teóricas las primeras explicaciones sobre este proceso, partiendo de las transformaciones culturales y materiales que siguieron a la caída del

\footnotetext{
${ }^{9}$ Sobre esta experiencia, entre otros, Franco (2008).

${ }^{10}$ Análisis de este proceso desde el punto de vista político y cultural, entre otros, Amaral (1997), Ollier (1986), Ponza (2010), Nahmías (2013), Goebel (2013), Spinelli (2013). ${ }^{11}$ Entre ellos: Torre (1983), escrito entre 1978 y 1979, Di Tella, (1983), Itzcovitz (1985), De Riz (1987).
} 
peronismo en 1955, la apertura al mundo, el impacto de la Guerra Fría, el fortalecimiento político del sindicalismo, el desarrollo y la modernización industrial en Córdoba y en las orillas del Paraná hasta Buenos Aires y la ola de movilizaciones masivas contra el poder militar, iniciada con el Cordobazo en $1969 .{ }^{12}$

Juan Carlos Torre, uno de los intelectuales más destacados de su generación, centrado entonces en las preocupaciones sobre la relación entre sindicalismo y peronismo, editó en 1983 Los sindicatos en el gobierno 1973-1976. Este fue escrito durante su estadía como profesor visitante en el Institute of Latin American Studies de la Universidad de Londres y el Latin American Centre de la Universidad de Oxford en 1978 y primera mitad de 1979, mientras paralelamente concluyó un libro crucial en el ya prolongado debate sobre los orígenes del peronismo, editado en 1990: La vieja Guardia sindical y Perón. Sobre los orígenes del peronismo. ${ }^{13}$

\section{La perspectiva político-social}

En Los sindicatos en el gobierno... construye una historia de la relación peronismo y sindicalismo durante el tercer gobierno peronista, que comienza con el análisis de la trayectoria, las transformaciones y la crisis de los sindicatos entre 1955 y 1973 y culmina con el giro político que significó el retorno de Perón al poder. A partir de allí aborda el análisis de los posicionamientos de sus dirigentes, en las distintas fases políticas que atravesó el gobierno peronista, en el permanente juego de presión por sus intereses.

Así señala que durante la presidencia de Héctor J. Cámpora, advirtieron que habían perdido el protagonismo que Perón les había otorgado, en favor de los jóvenes radicalizados, lo que los llevó a acercarse al «círculo íntimo» del anciano líder para modificar las relaciones de fuer-

\footnotetext{
12 Otro libro editado por Oxford University Press en Nueva York, en 1983 y por Grijalbo en Buenos Aires, en 1987, Soldados de Perón. Los Montoneros de Richard Gillespie, vino a iluminar este actor crucial en el desenlace de la experiencia del tercer gobierno peronista. El politólogo inglés durante su estadía en la Argentina entre 1975 y 1976, estudió la conformación y trayectoria de la principal organización guerrillera, Montoneros, basado en un nutrido aparato erudito que incluye libros académicos y de divulgación, prensa de información general y partidaria, además de entrevistas a sus principales integrantes realizadas en el país y en el exterior.

${ }^{13}$ Un relato del autor sobre esta experiencia en Hora y Trímboli ().
} 
za. Pues, la concertación del Pacto Social, entre el gobierno, la CGT y la CGE, que apuntaba a racionalizar la dinámica de precios y salarios, los colocaba en una participación subordinada que anulaba la posibilidad de cualquier tipo de reivindicación.

En la tercera presidencia de Juan Domingo Perón ante los ataques del poder sindical contra el Pacto Social, las constantes del enfrentamiento fueron la recuperación del valor perdido de los salarios y el avance de la participación de los asalariados en el ingreso nacional, frente a una mejora en la tasa de rentabilidad de las empresas. Estas, junto a la aceleración de la crisis económica tornaron inviable el Pacto. Los esfuerzos de negociación eran superados por los conflictos ilegales y los llevó a la búsqueda del auxilio oficial. En la última aparición pública de Perón, del 12 de junio de 1974, un mes antes de su muerte, amenazó a la multitud con abandonar la presidencia si persistía el sabotaje y el cuestionamiento a su gestión de gobierno.

En el último capítulo, titulado «Bajo los sucesores de Perón. Julio1974- Marzo 1976» Sintetiza su interpretación del comportamiento político de los sindicatos en la última etapa:

Hacia julio de 1974, dicho régimen político había sufrido un serio desgaste, en particular, en el plano económico-social. Restaba, no obstante, todavía vigente la voluntad aliancista del viejo caudillo. Con su muerte, fue, precisamente, esta voluntad la que comenzó a faltar en el gobierno. Más inspirados por el sectarismo al que los habían acostumbrado los 18 años de semi-legalidad política que por las sabias lecciones sobre el arte de conquistar y conservar el poder que Perón les había impartido, incansablemente, durante sus últimos días, sus sucesores se dedicaron a desmantelar, prolijamente, los acuerdos heredados y a proclamar que había llegado la hora de la reparación histórica (p.106)

Sigue la dinámica de los acontecimientos que culminaron con la caída de Gelbard, sucedido por el peronista histórico Gómez Morales y el posterior endurecimiento del gobierno de Isabel Perón, en su claro giro a la derecha, que condujo a la supresión de la izquierda sindical y al retorno a las negociaciones colectivas en el marco del dramático deterioro de la economía, devaluación de la moneda y desobediencia de los empresarios. Los líderes de la CGT y las «62 Organizaciones», mientras reiteraron su fidelidad a la presidenta, seguían trabajando por la firma de nuevos contratos, hasta la designación de Celestino Rodrigo que anun- 
ció una devaluación del $100 \%$ de la moneda, incremento de $175 \%$ de los combustibles y todos los servicios públicos lo cual impactó de lleno en las negociaciones salariales. La confrontación continuó y los líderes sindicales firmaron acuerdos salariales que alcanzaron un promedio de 160\%. Finalmente Isabel anunció la anulación de los mismos y ofreció un aumento salarial generalizado del $50 \%$. Ante el agravamiento de la tensión la CGT ordenó un paro de 48 horas que culminó en la renuncia del ministro Rodrigo y de José López Rega.

Los tramos finales muestran el último avance del sector sindical, el retiro temporario de la presidenta, y la gestión económica de Antonio Cafiero, quien intentó los ajustes y correcciones que sirvieran para postergar el desenlace catastrófico. Sin embargo, la vorágine especulativa y las luchas intersectoriales aceleraron las expectativas inflacionarias, la caída de la producción y el crecimiento de la desocupación condujeron a un último intento de concertación entre el Estado, la CGE y la CGT que resultó impotente, a lo que se sumó la acción de la guerrilla. Ante el fracaso de los sectores sindicales y políticos, el primer lock out empresario y la última ola de protestas contra la política de austeridad anunciada por el reemplazante de Cafiero, los militares se adueñaban del poder.

El segundo abordaje temprano de esta experiencia política, es el de Liliana de Riz que publicó en 1981 en México, Retorno y derrumbe. El último gobierno peronista, reeditado en Argentina en 1987. Desde un marco analítico inscripto la tradición gramsciana, esboza una explicación integral del tercer gobierno peronista, que enmarca en las peculiaridades del capitalismo argentino y la dinámica de la lucha de clases.

Como Torre, inicia el análisis remontándose a las políticas de los gobiernos civiles y militares que lo sucedieron después de 1955, centrando la atención en las relaciones de fuerza que se establecen entre las clases y fracciones de clases. Una clase capitalista heterogénea (burguesía industrial- vs. agraria) que no tuvo expresión político-partidaria que la representara y el peso sindical del movimiento obrero que hizo su entrada con el peronismo encuadrado desde el Estado y del propio Perón gravitando en ellos, apoyando, avanzados los sesentas, alternativamente a los sectores negociadores y a la guerrilla en un equilibrio inestable de compromisos con el que armó su estrategia. A esta agregó la conciliación con los partidos políticos, para enfrentar al enemigo común, la dictadura militar.

Llegado el peronismo al gobierno, en la etapa presidencial de Héctor J. Cámpora, la intensa movilización de los sectores de izquierda marcó 
la primera amenaza al proyecto económico y creó un clima de crisis de autoridad que preanunciaba la caída del presidente. A todo esto, Perón, fue tratando de consolidar sus relaciones con los partidos políticos, sectores sindicales y finalmente con las fuerzas armadas, mientras condenaba crecientemente a la izquierda peronista.

De camino hacia su tercera presidencia, los objetivos de Perón, según De Riz, eran en el plano internacional, fiel a su doctrina de la Tercera Posición, convertirse en el líder ideológico del Tercer Mundo, y en el interno, reconstruir el orden político nacional, la «democracia integral» para lograr la estabilidad política en un marco de referencia compartido y el «Programa de reconstrucción y liberación nacional» asociado al ministro Gelbard cuyo objetivo era la justicia social. Analizando el discurso político de Perón en 1973 señala que reiteraba los temas de su doctrina, pero articulados a nuevas ideas, incluso postula que propone «civilizar» a los argentinos y reeducarlos políticamente para no cambiar el sistema, sino los gobiernos. Finalmente explica el conflicto con la izquierda peronista que, enfrentada a los sectores sindicales acentuó la opción militar y concluyó en la expulsión de la primera que, desaparecido Perón retomaría el discurso del «verdadero peronismo».

En los capítulos finales analiza el «derrumbe» del proyecto de Perón y del gobierno, afirmando que Isabel Perón y José López Rega se lanzaron a una brusca reconversión de dicho proyecto y optaron por el sectarismo y el aislamiento. Mientras los sindicatos comenzaron a ejercer presión sobre el gobierno, logrando el desplazamiento de Gelbard y la separación de los dirigentes de los sindicatos combativos. Su sucesor, Gómez Morales, no logró el respaldo del gobierno para llevar a cabo su plan de austeridad y productividad y fue reemplazado por Celestino Rodrigo que tomó un conjunto de drásticas medidas, cuyo resultado fue paralizar las negociaciones paritarias entre sindicatos y empresarios y desató una movilización masiva en su contra. El enfrentamiento fue escalando hasta la declaración de una huelga de 48 horas dispuesta por la CGT en una clara derrota del gobierno. Luego se interna en los últimos tramos constituidos por avance sindical con la gestión de Antonio Cafiero en Economía y su fracaso y concluye con la explicación debacle del gobierno, la huelga empresarial, la impotencia de los partidos y la intervención militar. 


\section{Una historia «desde el interior del peronismo»}

Completa esta producción temprana, otro libro académico -escrito como los dos primeros, desde el exterior- proveniente en este caso de un integrante del tercer gobierno peronista, el economista Guido Di Tella. Este fue Secretario de Coordinación y Programación Económica durante la gestión de Antonio Cafiero en el Ministerio de Economía (septiembre de 1975-enero de 1976). En 1983 publicó en Buenos Aires PerónPerón 1973-1976, que construye desde otro ángulo de observación, el interior del partido y el gobierno peronista. Ello se hace visible en el recurrente juego comparativo del proceso que analiza con el peronismo histórico, marcando las rupturas y el peso de la tradición. Su enfoque se distingue de los anteriores, particularmente en el énfasis en la acción de la «subversión» como factor clave de ataque a la legalidad política y también respecto de las razones del fracaso del gobierno.

Consideró que no fue un gobierno que marchara a la deriva, sino que «lo esencial del desenlace» fue la rebelión del partido contra la oscilación hacia la derecha que la presidenta y sus allegados procuraban imponer. Esta rebelión, y no la ineptitud de la presidenta, creó el callejón sin salida donde se originó la caótica situación final; la ineptitud y la falta de condiciones de Isabel Perón fueron sin duda un factor coadyuvante, pero no la causa principal...» (p. 25).

Comienza su relato en la etapa que sucedió a la caída del peronismo en 1955, la división peronismo-antiperonismo, enfatizando en la apertura del país a los contactos internacionales, tanto en el plano cultural como económico, señalando el impacto que estos tuvieron en la modernización del país. Analiza en apretada síntesis las políticas de los dos gobiernos constitucionales y los tres militares del período, «la amenaza de la subversión» y «la retirada de los militares» que culmina en las negociaciones del general Alejandro Lanusse con Juan Domingo Perón.

En «Las presidencias peronistas», traza un panorama político de las mismas, desde la asunción de Héctor J. Cámpora, la hegemonía de la izquierda revolucionaria y de la izquierda en general, que preocupó a la iglesia y a las fuerzas armadas. Afirma que el Pacto Social constituía un aspecto central de la ideología peronista, un acuerdo de la distribución del ingreso tradicional entre los trabajadores y los empresarios, con implicancias para los sindicatos por la suspensión de las negociaciones colectivas, lo cual generó tensiones y críticas desde distintos sectores. 
Sostiene que desde el retorno de Perón al país se produjo la natural fricción entre un líder personalista y un presidente peronista, intensificada por la nueva orientación hacia la izquierda adoptada por éste, que generó el conflicto con la circunstancial coalición formada por la pequeña empresa, los sindicatos y el ala derecha que dominaba el círculo íntimo de Perón. «

Sobre la tercera presidencia de Perón sostiene que la misma se mantuvo en los marcos del sistema con el acento puesto en la reconciliación nacional, lo cual generó un clima político favorable, a pesar de algunas cuestiones preocupantes, la posible sucesión de Isabel y su afinidad política con López Rega, que constituían el ala derecha.

El anterior movimiento hacia la izquierda se revirtió, con la destitución de los gobernadores de Córdoba, Salta, Mendoza, Santa Cruz ${ }^{14}$ y la obligada renuncia del de Buenos Aires y los cambios en la UBA, entre otros. Mientras los grupos juveniles oscilaron entre la aceptación de la situación y el apoyo a Montoneros, con quienes Perón rompió el 1 de mayo de 1974.

Luego analiza los conflictos económicos y políticos que atravesaron a distintos sectores industriales, sindicales y empresariales, durante la gestión presidencial de Perón. Su muerte -dice- abrió la disyuntiva entre un gobierno viable encabezado por Isabel Perón o una nueva intervención militar.

La presidencia de Isabel Perón, asociada a José López Rega, puso en marcha un programa derecha que implicaba una ruptura con la tradición peronista, que el autor sintetiza en cinco objetivos. Se dirigía a grupos militares para acabar con la subversión, a través de grupos paramilitares, la Triple A, sin necesidad de su participación directa. El segundo objetivo era la eliminación de la infiltración izquierdista en la educación en general y en la Universidad de Buenos Aires, en particular. El tercero poner fin a las políticas anti empresarias, relativamente nacionalistas y operar un vuelco al capital extranjero. Lograr el sometimiento de los dirigentes sindicales rompiéndoles la relación con sus bases para lograr un cambio que los inhabilitara como factor de poder independiente. Por último pedir a los militares que abandonaran su neutralidad política.

Contra los objetivos del programa los Montoneros declararon que volcaban todas sus fuerzas a encabezar la resistencia popular. La intervención a la Universidad de Buenos Aires, duró sólo tres meses y, en

${ }^{14}$ Una investigación sobre este proceso en Alicia Servetto (2010). 
general la parte antisubversiva generó oposición, sus resultados fueron ambiguos y los ataques terroristas se intensificaron.

Por otra parte, los sindicatos reclamaron una mayor participación en la planificación y estrategia de las políticas nacionales, lo que generó una relación de desconfianza recíproca, pues la presidenta temía a su poder y las críticas a la política económica eran crecientes.

Avanzado el tiempo y acompañando el deterioro político y económico, el gobierno decidió llevar hasta sus últimas consecuencias el programa diseñado, designando a Celestino Rodrigo en el Ministerio de Economía con un programa drástico de devaluación. Enfrentado por los sindicatos, «que vacilaron -dice el autor- entre una tentativa de derribar a Rodrigo y López Rega y un plan más drástico encaminado a derribar al gobierno entero» (p.136). Llamaron a una huelga nacional y lograron la destitución de ambos, pero la crisis repercutió en el Ejército, con la separación del Comandante del Ejército y la designación en su lugar del general Jorge Rafael Videla.

El gobierno perdió la mayor parte de sus apoyos, la presidenta su autoridad. Fueron designados Ángel Robledo y Antonio Cafiero, en Interior y Economía, respectivamente, mientras Italo Luder asumió temporalmente la presidencia. A la expectativa inicial generada por el nuevo equipo de gobierno, el poder incontrolado de los sindicatos, la magnitud de sus demandas y su conducta poco responsable, contribuyó a crear el clima previo al golpe. A él se sumaron grupos empresarios y sectores antes afines.

Finalmente el retorno de Isabel Perón al cargo y el diseño de un plan de emergencia que a los ojos de los sindicatos, implicaba la disminución del salario, la caída de la inversión, el aumento de la desocupación, provocó una última oleada de huelgas. Sin embargo, los dirigentes sindicales vacilaban, todos esperaban el golpe. ${ }^{15}$

\section{El eje en el ejercicio del poder}

El último de los libros considerados de esta primera generación de estudios sobre el tercer peronismo es el de Victoria Itzcovitz, Estilo de gobierno y crisis politica (1973-76), editado en 1985, analíticamente enmarcado en las teorías del autoritarismo y la democracia, aborda cen-

\footnotetext{
${ }^{15}$ En los siguientes cinco capítulos, se analizan los hechos económicos.
} 
tralmente la problemática política, vinculándola a la forma de ejercer, gestionar y negociar desde el poder.

Revisando la tradición política del peronismo y la complejidad del mismo en la coyuntura de su retorno, analiza el comportamiento pendular de Perón hacia los extremos. Desde su apoyo a la izquierda en el momento inicial durante la designación de Cámpora y su equipo, así como de los gobernadores posteriormente descalificados como «infiltrados» y el estímulo a los sectores más radicalizados, hasta el pasaje al peronismo histórico que le lleva a una reversión de alianzas, privilegia a los sindicatos y ataca a la juventud radicalizada, situación que permanece hasta la asunción de la presidencia por parte de Isabel Perón, cuando pasa al ataque frontal al gobierno.

Luego analiza como esta mecánica del ejercicio del gobierno se proyectó a los conflictos provinciales y la participación sindical, y en el siguiente capítulo la pérdida del monopolio de la fuerza y sus consecuencias sobre el régimen democrático, se refiere a la delegación del primero a grupos paraestatales y la cesión de un espacio político a las FF.AA que pasaron a controlar el tema de la subversión , para finalmente tratar el manejo realizado de los poderes del Estado en la resolución de la crisis, en el Senado (sucesión presidencial-Luder) para evitar el golpe.

En 1058 días del período peronista el país tuvo 5 presidentes y 40 ministros, a razón de 5 por cartera. Los que más permanecieron fueron Bienestar social (768 días) y Trabajo (732). ${ }^{16}$

\section{Consideraciones finales}

El cuadro compuesto por estos cuatro libros académicos que hemos reseñado, editados en la Argentina Democrática reinaugurada en 1983, presenta desde distintos ángulos, los primeros análisis sobre el retorno del peronismo al gobierno, iluminando a los actores centrales y su peso en el desenlace catastrófico. En síntesis, se trata de la historia de un fracaso. Punto este último en el cual coinciden el conjunto de los auto-

\footnotetext{
${ }^{16} \mathrm{Al}$ final explica: «...lo que se intentó fue desentrañar un estilo de gobierno, una ética del comportamiento político, que tuvo que ver con una utilización sectorizada y partidista de los resortes institucionales del poder político, y con una concepción autoritaria, que distanció de a poco a las autoridades de la población que le había dado su apoyo, al punto que, al final del recorrido, no pudieron reclamar siquiera la ayuda de los grupos minoritarios para los que habían gobernado...» (p. 91).
} 
res y ello se hace visible en algunos de ellos desde la inspiración del título, Retorno y Derrumbe..., Liliana De Riz. Otros en la dedicatoria: «Para aquellos que creyeron con esperanza y recuerdan con pesar», Guido Di Tella, o en la Introducción: «...las razones que provocaron el deterioro profundo que afectó al aparato de estado y a los grupos que hegemonizaban el poder político en dicho período y que arrastraron consigo a todo el régimen y produjeron su caída», Victoria Itzcovitz.

Los dos primeros trabajos, volcados al análisis de los sujetos sociales y su relación con el poder político, siguieron con distinta intensidad la narrativa de los acontecimientos políticos. En el caso de Torre, a través de la trayectoria de los sindicatos que, aferrados a sus tradiciones de lucha resistieron el Pacto Social y en definitiva no aceptaron el proyecto político integrador que Perón trajo a su retorno, el cual incluía al sector empresarial y a la mayor parte de los partidos políticos. También rechazado por el ala derecha del peronismo que lo sucedió.

Liliana De Riz, que desde un enfoque integral que introduce la dinámica del conflicto de clases, coincide en líneas generales con la interpretación del desenlace. Ofrece un interesante análisis del malogrado proyecto de Perón, analizando lo tradicional y lo que había de nuevo en él, producto de la experiencia recogida en los últimos tramos de su exilio.

Mientras Di Tella, desde una perspectiva política que mira el proceso desde el interior del mismo, distingue los tres momentos del gobierno y subraya que el giro a la derecha de la última fase, que buscó la negociación y el apoyo de las fuerzas armadas, fue clave en la descomposición partidaria que precipitó el golpe.

Para Victoria Itzcovitz el nudo del problema de la crisis que concluyó en el golpe de 1976, está vinculado a la naturaleza del peronismo y a su tipo de liderazgo, cuyo estilo político lo colocó tradicionalmente, por encima del marco institucional del Estado.

El conjunto de los trabajos tratados coincide en explorar las razones del fracaso del tercer gobierno peronista, que tan alto nivel de adhesión y encontradas expectativas había generado en distintos sectores políticos y sociales. Estos excedían en mucho al peronismo histórico y por tanto las adhesiones y las expectativas hacia Perón, en parte generadas por él mismo durante su largo exilio, descansaban en proyectos de país, distintos y antagónicos que inevitablemente chocaron desde que el peronismo asumió el gobierno. 


\section{Referencias bibliográficas}

Amaral, S. (1997). De Perón a Perón (1955-1973), Nueva Historia de la Nación Argentina 7. La Argentina del siglo XX. Buenos Aires, Argentina: Planeta.

Calvert, S. y Calvert, P. (1989). Argentina. Political culture and Instability. Pittsburgh, Estados Unidos: University of Pittsburgh Press.

Cavarozzi, M. (1983). Autoritarismo y Democracia (1955-1983). Buenos Aires, Argentina: CEAL.

De Riz, L. (1981). Retorno y derrumbe. El último gobierno peronista. Buenos Aires, Argentina: Folios.

Devoto, F. (Comp.) (1994). La historiografia argentina en el siglo XX (II). Buenos Aires, Argentina: CEAL.

Di Tella, G. (1983). Perón-Perón 1973-1976. Buenos Aires, Argentina: Sudamericana.

Floria, C. (Comp.). (1981). Reflexiones sobre la Argentina Politica. Buenos Aires, Argentina: Belgrano.

Franco, M. (2008). El exilio, argentinos en Francia durante la dictadura. Buenos Aires, Argentina: Siglo XXI.

Franco, M. y Levín, F. (Comps.). (2007). Historia reciente. Perspectivas y desafíos para un campo en construcción. Buenos Aires, Argentina: Paidós.

Gillespie, R. (1982). Soldados de Perón. Los Montoneros. Buenos Aires, Argentina: Grijalbo.

Goebel, M. (2013). La Argentina partida. Nacionalismos y politicas de la historia, Buenos Aires, Argentina: Prometeo.

Halperín Donghi, T. (1986). Un cuarto de siglo de historiografía argentina (1960-1985), Desarrollo Económico, 100, 487-520.

Hora, R y Trímboli, J. (1994). Pensar la Argentina. Los historiadores hablan de historia y de politica, Tulio Halperin Donghi, Daniel James, Oscar Terán, Hilda Sábato, Natalio Botana, José Carlos Chiaramonte, Beatríz Sarlo, Juan Carlos Torre. Buenos Aires, Argentina: El cielo por Asalto.

Itzcovitz, V. (1985). Estilo de gobierno y crisis politica (1973-1976). Buenos Aires, Argentina: CEAL. 
Lesgart, C. (2002). Usos de la Transición a la Democracia. Estudios Sociales, 22-23.

Luna, F. (1983). Golpes militares y salidas electorales. Buenos Aires, Argentina: Sudamericana.

Nahmías, G. (2013). De la Unidad imposible a la violencia política (Argentina 1969-1973). Buenos Aires, Argentina: Edhasa.

Novaro, M. (2006). Historia de la Argentina Contemporánea. De Perón a Kirchner, Buenos Aires, Argentina: Edhasa.

Novaro, M.y Palermo, V. (2003). La Dictadura Militar 1976-1983, Historia Argentina 9. Buenos Aires, Argentina: Paidós.

O’Donell, G. (1982). 1966-1973. El Estado Burocrático Autoritario. Buenos Aires, Argentina: Belgrano.

Ollier, M. M. (1986). El fenómeno insurreccional y la cultura politica (19691973). Buenos Aires, Argentina: CEAL.

Ollier, M. M. (2005). Golpe o revolución. La violencia legitimada, Argentina 1966-1973. Buenos Aires, Argentina: Universidad de 3 de Febrero.

Pinto, J. (1988). (Comp) Ensayos sobve la crisis politica argentina, (3 vol.). Buenos Aires, Argentina: CEAL.

Ponza, P. (2010). Intelectuales y violencia politica 1955-1973. Historia intelectual, discursos politicos y concepciones de lucha armada en la Argentina de los años sesenta-setenta. Córdoba, Argentina: Babel.

Potash, R. (1981). El Ejército y la politica en la Argentina 1928-1945 De Yrigoyen a Perón y 1945-1962 De Perón a Frondizi. Buenos Aires, Argentina: Sudamericana.

Romero, L. A. (1994). Breve Historia Contemporánea de Argentina. Buenos Aires, Argentina: Fondo de Cultura Económica.

Romero, L. A. (1996). La historiografía argentina en la democracia: los problemas de la construcción de un campo profesional, Entrepasados: revista de historia, 10.

Rouquié, A. (1981 y 1982). Poder militar y sociedad politica en la Argentina, I. hasta 1943 y II. 1943-1973, Buenos Aires, Argentina: Emecé.

Rouquié, A. y Schvarzer, J. (Comp.). (1985) ¿Cómo renacen las democracias?, Buenos Aires, Argentina: Emecé. 
Servetto, A. (2010). 73/76. El gobierno peronista contra las «provincias montoneras». Buenos Aires, Argentina: Siglo XXI.

Sigal, S. (1991). Intelectuales y poder en la década del sesenta. Buenos Aires, Argentina: Puntosur.

Spinelli, M. E. (2008). La impronta de la 'transición democrática' en la historiografía sobre la segunda mitad del siglo XX argentino. Estudios de Filosofía Práctica e Historia de las ideas, 9 (10), 11-28.

Spinelli, M. E. (2013). De antiperonistas a peronistas revolucionarios. Las clases medias en el centro de la crisis politica argentina (1955-1973). Buenos Aires, Argentina: Sudamericana.

Tcach, C. (1996). Partidos políticos y dictadura militar en Argentina (1976-1983). En: Dutrenit, S. (Coord.). Diversidad partidaria y dictaduras: Argentina, Brasil y Uruguay, pp. 25-88. México, México: Instituto de Investigaciones Dr. José María Luis Mora.

Tcach, C. (Comp.). (2003). La politica en consignas. Memoria de los setenta. Rosario, Argentina: Homo Sapiens.

Torre, J. C. (1983). Los sindicatos en el gobierno 1973-76. Buenos Aires, Argentina: CEAL.

Torre, J. C. (2004 [1983]). El gigante invertebrado. Los sindicatos en el gobierno argentino (1973-1976). Buenos Aires, Argentina: Siglo XXI.

Waldman, P. y Garzón Valdéz, E. (Comps.). (1983). El poder militar en la Argentina 1976-1981. Buenos Aires, Argentina: Galerna. 